\title{
Judicialização e a Efetividade dos Direitos Sociais: o "Estado de Coisas Inconstitucional", no encarceramento brasileiro
}

\author{
Judicialization and the Effectiveness of Social Rights: the \\ "Unconstitutional State of Things", in Brazilian incarceration
}

Bianca Medran Moreira ${ }^{1}$

Raquel Fabiana Lopes Sparemberger ${ }^{2}$

\begin{abstract}
RESUMO
O presente estudo tem por escopo analisar a questão da judicialização dos direitos sociais, a partir da decisão do Supremo Tribunal Federal, que declarou "Estado de Coisas Inconstitucional", em relação a superlotação carcerária do Brasil. Para tanto, busca as raízes da exigibilidade dos direitos sociais na humanização do sistema jurídico, após o advento da Constituição Federal e, a partir de uma investigação jurídica, sem a menor pretensão de esgotar a temática, a pesquisa bibliográfica, através do método dedutivo, pretende demonstrar, primeiramente, porque os direitos sociais são exigíveis após a constitucionalização do direito. E, em um segundo momento, propõe-se a refletir sobre o papel do poder judiciário na agenda de promoção dos direitos humanos, diante de patologias sociais, como a situação do crônico desaparelhamento do sistema carcerário pátrio, que gera a total privação dos direitos mais básicos aos presos.
\end{abstract}

PALAVRAS-CHAVE:

Exigibilidade; Direitos sociais; Superlotação; Carcerária.

\section{ABSTRACT}

The present study aims to analyze the judicialization of social rights, based on the Supreme Court analysis of the "Unconstitutional State of Affairs" in Brazil's prison system. From a juridical investigation, without the least pretension to exhaust the subject, the bibliographical research, through the deductive method, seeks to demonstrate: First, why social rights are enforceable after the constitutionalization of the law. Secondly, it tries to reflect the role of the court in the human rights promotion, in case of social pathologies, such as the situation of the chronic deprivation on the over crowed prison system.

\footnotetext{
${ }^{1}$ Mestranda em Direito pela Fundação Escola Superior do Ministério Público-FMP-RS. Especialista em Direito Constitucional pela PUC-RS. Advogada.Email.bimedran@gmail.com.

2 Pós-doutora em Direito pela Universidade Federal de Santa Catarina - UFSC. Doutora em Direito pela Universidade Federal do Paraná - UFPR. Mestre em Direito pela UFPR. Professora Adjunta da Universidade Federal do Rio Grande - FURG. Professora do Programa de Mestrado em Direito da Universidade Federal do Rio Grande - FURG. Professora dos cursos de graduação e do Programa de Mestrado em Direito da Faculdade de Direito da Fundação Escola Superior do Ministério Público - FMP/RS. Tem experiência na área de Direito, com ênfase em Teoria Geral do Direito, Direito Constitucional, Direitos Humanos, América Latina e questões decoloniais. Professora pesquisadora do CNPq e FAPERGS. Pesquisadora dos Grupos de Pesquisa Tutelas à efetivação dos direitos indisponíveis, Linha Tutelas à efetivação de Direitos Públicos Incondicionados, coordenadora do Grupo de Pesquisa Direito constitucional e violência da FURG. Endereço eletrônico: fabiana7778@hotmail.com.
} 


\section{KEYWORDS:}

Enforceability; Social rights; Over crowed;Prison system.

\section{INTRODUÇÃO}

É importante reconhecer que a incidência dos valores constitucionais no direito reflete a preocupação contemporânea de que a interpretação de todo o ordenamento jurídico seja primordialmente voltada à promoção da dignidade humana. Nesse contexto, o trabalho pretende refletir sobre a judicialização e a efetividade dos direitos sociais, a partir, especialmente, da análise do tratamento dado, no exercício de sua função contra majoritária, pelo Supremo Tribunal Federal, à superlotação carcerária, através do julgamento da ADPF $347^{3}$, que declarou o chamado "Estado de Coisas Inconstitucional", no encarceramento brasileiro.

O trabalho é divido em duas principais partes. Busca, de início, no segundo capítulo, analisar a constitucionalização do direito e a exigibilidade jurídica dos direitos sociais. Abordando a legitimidade do poder judiciário para decidir sobre direitos sociais. Reconhecendo que, quando os interesses de minorias são escandalosamente desrespeitados (geralmente pelo descumprimento dos encargos vinculantes dos outros órgãos), o poder judiciário possui, sim, legitimidade para determinar a implementação depolíticas públicas, apesar de esta não ser sua atribuição primária, examinando, por outro lado, os problemas disso.

Desconstrói, resumidamente, o argumento da chamada "reserva do possível", para casos de desumanidade obscena e, no terceiro capítulo, discorre sobre o julgamento da ADPF 347, trazendo a crítica a esta decisão, comentando e mensurando seus efeitos. Faz-se, ainda, breves considerações sobre a superlotação carcerária e desumanização do sistema prisional. Em considerações finais, comenta sobre a jurisdição constitucional de efeito pedagógico, e trata, rapidamente sobre ativismo dialógico.

\footnotetext{
${ }^{3}$ BRASIL. Supremo Tribunal Federal. ADPF 347. Protocolada em 27 de maio de 2015. Brasília, 2015. Disponível em: http://portal.stf.jus.br/processos/detalhe.asp?incidente=4783560. Acesso em: 11.jul.2019.
} 


\title{
2 A CONSTITUCIONALIZAÇÃo DO DIREITO, A TUTELA DO SUJEITO DE DIREITO NA CONCEPÇÃO CONTEMPORÂNEA E A JUDICIALIZAÇÃO DE DIREITO SOCIAIS
}

Impossível entender as transformações do direito e, posteriormente, cogitar a exigibilidade jurídica de direitos sociais, sem analisar o contexto humanista e liberal que impulsionou a Revolução Francesa, do século XVIII, e determinou um marco incomensurável na história da humanidade:

\begin{abstract}
O velho mundo passou por uma renovação radical, guiada pelos princípios da razão humana e pelo objetivo de alcançar a felicidade do homem. A realização desse objetivo parecia requerer agora que o fardo dos séculos precedentes fosse rejeitado. Aplicado ao direito, esse programa significava que a proliferação de normas jurídicas deveria ser drasticamente reduzida, que o desenvolvimento gradual do direito deveria ser substituído por um plano de reforma e por uma abordagem sistemática, e, por fim, que não se deveria emprestar autoridade absoluta nem aos valores tradicionais, como direito romano, nem aos juristas e juízes eruditos, que se proclamavam "oráculos" do direito. Os velhos costumes e os livros autorizados deveriam ser substituídos por um novo direito livremente concebido pelo homem moderno, cujo único princípio diretor fosse a razão. Esse novo direito deveria ser isento de qualquer obscurantismo. Ele constituiria um sistema claro e aberto, compreensível para o povo, pois, de agora em diante, o direito deveria estar a serviço do povo. ${ }^{4}$
\end{abstract}

O surgimento do chamado individualismo ou liberalismo, ao instituir a supervalorização do homem, fez surgir o Estado de Direito, com regras previamente estabelecidas para gerar segurança jurídica. A exaltação artística, cultural, política e filosófica deu asas aos ideais libertários e fez nascer nova consciência aos povos. A codificação surge justamente do advento do Estado Liberal e da afirmação do individualismo jurídico, com a finalidade de assegurar espaço de autonomia aos indivíduos, principalmente no campo econômico.

Visualiza-se, nitidamente, que a partir dos acontecimentos do século XVII, o homem sentiu necessidade de limitar o poder do governante e submetê-lo também à legalidade, decretando, assim, o fim do Estado opressor. Outro anseio dessa época foi o de garantir autonomia aos indivíduos, especialmente na esfera econômico-patrimonial. Por isso, o Estado Liberal clássico foi marcado por uma rígida delimitação de seus poderes de intervenção na esfera jurídica privada. A própria Constituição francesa de 1795, para Paulo Bonavides, é o

\footnotetext{
${ }^{4}$ CAENEGEM, Raoul Charles Van. Uma introdução histórica ao direito privado. Trad. Carlos Eduardo Lima Machado. 2 ed. São Paulo: Martins Fontes, 1999, p. 163, grifo nosso.
} 
protótipo do Estado Liberal, "o triunfo da sociedade sobre o Estado" se funda a liberdade real dos homens. Sem o direito, cada um estaria à mercê do arbítrio do Estado. Para os iluministas, a plenitude da pessoa dava-se com o domínio sobre as coisas. Os códigos, por isso, possuíam como paradigma o cidadão munido de patrimônio:

\footnotetext{
Na verdade, a codificação, especialmente a codificação civil, cristalizou os valores do liberalismo burguês da época, que tinha por fundamento central a patrimonialização das relações civis. Era o predomínio do ter sobre o ser. O homem destinatário da codificação civil sempre foi aquele dotado de patrimônio. E há uma justificação histórica porque, no seu momento, representou a emancipação do homem. ${ }^{6}$
}

Para essa cristalização de valores, incrementou-se o constitucionalismo, isto é, a predominância de uma Constituição ordinariamente escrita, na qual estivessem consagrados os direitos e garantias fundamentais do cidadão e as vedações ao poder do Estado. Mas um estranho fenômeno então ocorreu: as Constituições que foram criadas praticamente não editaram normas no que tange às relações entre particulares, pois estavam mais preocupadas com o sentido do Estado mínimo, naturalmente em consonância ao anseio de limitação do poder político do Estado efervescente na época. Deixaram então para os Códigos a regulação dessas matérias, conforme as ideias iluministas de autonomia e individualismo do homem.

Foi possível perceber na codificação liberal, a necessidade da propriedade à total realização da pessoa, no Estado Social, posteriormente, será possível ver submergir a pessoa humana, na sua potencialidade ética e moral. Entender o homem, apenas sob o prisma do patrimônio, exclui a grande maioria: assim, no fim do século XIX e início do século XX, o denominado Estado Social surge, em substituição ao Estado Liberal.

Considera-se Estado Social aquele que é regido por uma Constituição que trata de regular também a ordem econômica e social, exatamente no que difere do Estado Liberal, no qual a constituição não se preocupava com os direitos econômicos e sociais, mas apenas com a delimitação do poder político e a consolidação dos direitos individuais. O Estado social tentou transpor a contradição entre a igualdade política e desigualdade social, pois o liberalismo não oferecia nenhuma solução às desigualdades social.

\footnotetext{
${ }^{5}$ BONAVIDES, Paulo. Curso de Direito Constitucional. 13 ed. São Paulo: Malheiros, 2003. ${ }^{6}$ Ibid., p. 862.
} 
Dentre outros fatores, é inegável que a Revolução Industrial e a livre concorrência trouxeram condições desumanas de vida e de trabalho, que culminaram na manifestação da insuficiência do reconhecimento apenas dos direitos individuais. A sociedade constatou que as liberdades, se desacompanhadas de mínima seguridade social, direitos laborais, econômicos (como o direito ao trabalho e ao salário justo) e culturais (como a educação), não permitem a existência digna das pessoas.

Nesse sentido, Almeida e Coelho:

No limiar do século XX, procedeu-se a uma certa ruptura com a ideia de liberdade quase total - em razão da desigualdade quase inevitável que o sistema liberal engendra - com a profunda ingerência do Estado na proteção dos vulneráveis. Vislumbra-se, aqui, uma evidente preocupação da inércia estatal de outrora que, em parte, ensejou as desigualdades atualmente experimentadas. Inaugura-se, de certa forma, a preponderância do interesse público sobre o interesse individual. ${ }^{7}$

Surge, então, o Estado Social e a função do Estado em prol do coletivo, que passa a intervir nos campos econômico e social, para assegurar a tutela dos mais vulneráveis, através de limitações do poder econômico. O surgimento de movimentos sociais, diante da realidade complexa, foi forçando o Estado a abandonar a neutralidade e assumir uma postura protetora de determinados interesses sociais. O Estado passou a ser mais intervencionista e, como consequência, tem-se modificações nas funções do Direito. Afinal, aquela moldura individualista não consegue enquadramento em uma sociedade que passa a preocupar-se em garantir a permanente integração do homem.

O Estado Social, então, limita o poder econômico e tutela, mais que os indivíduos; tutela o trabalho, a educação, a cultura, o lazer, a infância, a saúde, a seguridade social, a maternidade, a moradia. Este passa a atuar justamente para fazer prevalecer o interesse coletivo, e possibilitar, publicamente, a afirmação da dignidade humana. Houve assim, também, o surgimento de direitos de novas dimensões da cidadania, a exemplo da legislação de proteção do consumidor e ao meio ambiente,pertinentes ao novo mundo globalizado.

A fim de tornar possível a plena tutela dos indivíduos, na concepção contemporânea, o valor essencial do nosso sistema jurídico passa a ser a dignidade da pessoa humana, que exerce

\footnotetext{
${ }^{7}$ ALMEIDA, Renato Franco de; COELHO, Aline Bayerl. Princípio da demanda nas ações coletivas do Estado Social de Direito. Revista de Direito do Consumidor, n. 50. São Paulo: Revista dos Tribunais, abr.jun., 2004, p. 121.
} 
força sobre toda a ordem jurídica. A dignidade humana, sob essa ótica, deve ser entendida como um fim, e não, meramente, como um meio para alcançar outros objetivos, menos ainda, apenas como norma programática.

Sobre o assunto entende Alexandre de Moraes que:

\begin{abstract}
A dignidade é um valor espiritual e moral inerente à pessoa, que se manifesta singularmente na autodeterminação consciente e responsável da própria vida e que traz consigo a pretensão ao respeito por parte das demais pessoas, constituindo-se um mínimo invulnerável que todo estatuto jurídico deve assegurar, de modo que, somente excepcionalmente, possam ser feitas limitações ao exercício dos direitos fundamentais, mas sempre sem menosprezar a necessária estima que merecem todas as pessoas enquanto seres humanos. ${ }^{8}$
\end{abstract}

E é justamente essa preocupação com o ser humano que deve orientar todos os ramos no Direito. O ordenamento jurídico, nesse contexto, é pautado pelos valores existenciais. Os institutos jurídicos, por sua vez, instrumentalizados com a prioridade de promover o integral desenvolvimento do homem. O direito contemporâneo está preocupado com a proteção da pessoa, concretamente considerada. Ele deve se adequar à realidade e aos fundamentos constitucionais vigentes. E tal adequação se funda na primazia do ser humano. Seus valores personalíssimos devem ocupar, pois, o centro das relações jurídicas.

Sena sociedade moderna os valores fundados na dignidade da pessoa humana prevalecem, resta a necessidade de restaurar a primazia da pessoa humana em todas as relações, e compatibilizar o direito com os fundamentos constitucionais. Apresenta-se esse movimento (de trazer a dignidade do ser humano ao centro epistemológico do direito) com nome de "repersonalização". O movimento atual é, então, o de colocar o ser humano no centro do Direito. Nas palavras de Luiz Edson Fachin, "a defesa da vida, plena e digna, é a única seiva que pode animar o direito". 9

A tutela constitucional ao direito à vida, prevista nos artigos $5^{\circ}$ e 170 , da nossa Carta Maior, que tem como prioridade o condicionamento da ordem econômica à garantia de uma existência digna a todo ser humano, ensina que todas as normas infraconstitucionais precisam

\footnotetext{
${ }^{8}$ MORAES, Alexandre de. Direito constitucional. 13a . ed. São Paulo: Atlas, 2003, p. 50, grifo do autor.

${ }^{9}$ FACHIN, Luiz Edson. Estatuto jurídico do patrimônio mínimo. Rio de Janeiro: Renovar, 2001.
} 
se submeter aos valores que a sociedade brasileira identifica como prevalentes que se consolidam como princípios constitucionais, especialmente vida e dignidade.

A questão é: há fatos que se impõem perante o Direito, "há condutas que desenvolvem comportamentos não adredemente regulados e, ainda, aquelas que se chocam com uma regulação anterior. Esses comportamentos impõem uma transformação do regulamento anterior, uma nova regulamentação"10. A atualidade é palco da busca de se considerar as pessoas em suas complexidades e historicidades. Ou seja, a lógica positivista é agora invertida: não se parte mais do sistema para o caso concreto. A realidade é que deve fazer nascer os ideais de justiça e a própria segurança jurídica.

O Positivismo, apesar de ser uma genial tentativa de transformar o direito em uma ciência propriamente dita, é criticado pela sua pretensão de um controle cognitivo absoluto da realidade e pela tentativa de aprisionar o homem e enclausurá-lo a um sistema fechado. A visão contemporânea revoluciona os paradigmas de interpretação utilizados até então. Supera-se a ideia de um sistema fechado apenas de descrição, criado pelas escolas clássicas.

A mudança no modo de pensar o direito, um outro sentido de sujeito de direito, diferente do sistema clássico que foi construído de modo abstrato, e a necessidade do reconhecimento de novos valores jurídicos configuram a superação do sistema que, no entanto, deve ser reconhecido por sua base, embora ela não se baste por si só. A tutela jurídica que a legislação oferece deverá estar vinculada intimamente aos valores sociais consagrados constitucionalmente. E a função do aplicador da lei é de instrumentalizar o direito e atuar para cumprir a constituição e valorizar o ser humano, especialmente na sua condição de cidadão.

Atualmente, com o objetivo de superar o sujeito abstratamente considerado pela teoria clássica, procura-se, agregando-se à noção de cidadania, a construção do sujeito concreto. Quando a Constituição Federal de 1988 tutela o direito à vida e coloca em primeiro lugar o direito à personalidade, trata de um novo sujeito, alguém que tem uma existência concreta, com direitos constitucionalmente garantidos, de toda ordem. Quando se fala em direito à vida, o conceito não se refere apenas à condição biológica. $\mathrm{O}$ direito à vida diz respeito a uma vida

\footnotetext{
${ }^{10}$ FACHIN, Luiz Edson. Teoria crítica do direito civil. 2 ed. Rio de Janeiro: Renovar, 2003, p. 224.
} 
digna, com todas as suas implicações. Trata-se do direito a uma existência digna, também com assento constitucional.

Cumpre salientar, ainda, que é nitidamente incorreto privilegiar a previsão legal, que é apenas teórica, dando aos fatos importância mínima. O direito é um fenômeno profundamente social e dinâmico. A noção de sujeito se altera na exata medida em que se constroem novas relações sociais. Se na visão clássica o indivíduo é abstratamente considerado, a perspectiva contemporânea é de superar essa visão e construir um sujeito concreto.

Para Gustavo Tepedino, a conquista principal atual é a descoberta do significado relativo e histórico dos conceitos jurídicos, que sempre foram tidos como neutros e absolutos. Cada instituto jurídico se torna insuficiente fora de um contexto histórico ou cultural. Evidentemente, já alertava Ronald Dworkin, que "a representação do direito como um sistema apenas de regras não ampara a complexidade e sofisticação que deve ter o modelo que se necessita e se é capaz de construir" ${ }^{\prime 1}$. Há os que ainda vão além e ousam dizer que o direito passou a ser o direito constitucional aplicado, pois, nele se detecta o projeto de vida em comum que a Constituição impõe. Nota-se, na concepção contemporânea, assim, uma progressiva tutela constitucional, ampliando o âmbito dos interesses protegidos.

Nas palavras de Fernando Atria:

Na prática política, especialmente em vários dos países latino americanos (Argentina e Chile entre outros), a ideia de utilizar foros judiciais para lutar pelo progresso social e político, se fez mais e mais corrente, e estes foros consequentemente mais e mais importantes ${ }^{12}$.

Assim, em que pese reconhecer-se que:

[...] a implementação dos direitos econômicos, sociais e culturais depende em parte de atividades de planificação, previsão orçamentária e execução que por natureza correspondem aos poderes políticos, sendo limitados os casos que o poder judicial pode levar a cabo a tarefa de suprir a inatividade daqueles ${ }^{13}$.

De tal forma que o Poder judiciário pode, sim, excepcionalmente, determinar e acompanhar políticas públicas, quando diante de insuportável violação de direitos humanos. E

\footnotetext{
${ }^{11}$ DWORKIN, Ronald. Levando os direitos a sério. São Paulo: Martins Fontes, 2002.

12 ATRIA, Fernando. "Existem direitos sociais?" In: MELLO, Cláudio Ari (coord.). Os desafios dos direitos sociais. Porto Alegre: Livraria do Advogado, 2005, p. 28.

13 ABRAMOVICH, Victor; COURTIS, Christian. Los derechos sociales como derechos exigibles. Madrid: Trotta, 2002, p. 44.
} 
isso não viola o princípio da separação de poderes, pois apenas afirma a necessidade urgente de que os outros poderes estabeleçam e executem tais políticas.

Nesse sentido:

\begin{abstract}
Além disso, assume caráter emergencial uma crescente conscientização por parte dos órgãos do Poder Judiciário, de que não apenas podem como devem zelar pela efetivação dos direitos fundamentais sociais, mas que, ao fazê-lo, haverão de obrar com máxima cautela e responsabilidade, seja ao concederem (seja quando negarem) um direito subjetivo a determinada prestação social, ou mesmo quando declararem a inconstitucionalidade de alguma medida estatal com base na alegação de uma violação de direitos sociais, sem que tal postura, como já esperamos ter logrado fundamentar, venha a implicar necessariamente uma violação do princípio democrático e do princípio da separação dos Poderes. Neste sentido (e desde que assegurada atuação dos órgãos jurisdicionais, quando e na medida do necessário) efetivamente há que dar razão a Holmes e Sunstein quando afirmam que levar direitos a sério (especialmente pelo prisma da eficácia e efetividade) é sempre também levar a sério o problema da escassez. Parece-nos oportuno apontar aqui (mesmo sem condições de desenvolver o ponto) que os princípios da moralidade e eficiência, mas também os correlatos princípios (e deveres) de publicidade e transparência, que direcionam a atuação da administração pública em geral, assumem um papel de destaque nesta discussão, notadamente quando se cuida de administrar a escassez de recursos e potencializar a efetividade dos direitos sociais. ${ }^{14}$
\end{abstract}

É certo que o adimplemento de direitos sociais é oneroso e exige prestações positivas. Por isso é importante dizer que os obstáculos artificiais e a indevida manipulação de a parente atividade financeira do Estado, para frustrar erradicação de grave violações humanitárias, não pode ser chancelada, sob o mando do instituto da chamada "reserva do possível". O Estado, assim, precisa provar, pelo menos, "melhores esforços", para eximir-se, justificadamente, de suas obrigações prestacionais. E, no que tange à questão da deferência, vale, ainda, referir que:

[...] as obrigações positivas são a área por excelência para dar respeito e acreditar que o equilíbrio do legislativo é digno de respeito. Mas isso é, obviamente, baseado na suposição de que o legislativo concedeu o devido respeito aos direitos econômicos e sociais, pelos quais é considerado democraticamente responsável - suposições que podem se manter nos tradicionais estados de bem-estar social, nas chamadas circunstâncias "normais" de estabilidade e solidariedade, mas são muito menos defensáveis em condições de ruptura e crise fiscal, desacordo ideológico, disfunção legislativa e política fiscal internacionalmente controlada - condições muito mais prováveis de se manter, na maioria dos lugares ${ }^{15}$.

\footnotetext{
${ }^{14}$ SARLET, Ingo Wolfgang; FIGUEIREDO, Mariana Filchtiner. Reserva do possível, mínimo existencial e direito à saúde: algumas aproximações. Revista de Doutrina da $4^{\mathbf{a}}$ Região, Porto Alegre, n. 24, jul, 2008. Disponível em: http://www.revistadoutrina.trf4.jus.br/artigos/edicao024/ingo_mariana.html. Acesso em: 12.set.2019.

15 YOUNG, Katharine Galloway. Proportionality, reasonableness, and economic social rights. In: JACKSON; Vicki C. TUSHNET, Mark (eds.). Proportionality: new frontiers, new challenges, 2017, p. 26.
} 
Onde, quando e como a deferência deve ser aplicada depende, pois, do grau de maturidade de cada democracia e do seu contexto político, social e cultural. Mas a verdade é que Katharine Galloway Young está certa ao afirmar que "se os tribunais levassem totalmente a sério os direitos sociais e a incapacidade de proteção estatal deles, a deferência seria deixada de lado e os provimentos seriam rigorosos, para proteger necessidades essenciais". ${ }^{16}$ Ainda mais, quando, em democracias falhas, "compromissos eleitoreiros" dos outros poderes, impedem implementação de políticas públicas urgentes, como é, inegavelmente, o caso do caos carcerário brasileiro. Afinal, "mexer com direitos dos presos é uma agenda complicada no país. Ela é inclusive um contrassenso para os políticos, que podem até perder voto por causa disso" $" 17$ (IHU, 2018).

Inegável a evidente resistência da sociedade civil ao enfrentamento do tema. Provavelmente por incompreensão crucial acerca da questão, pois não se trata de defender o bem-estar da população carcerária, embora isso fosse legítimo, mas de prezar até pela própria segurança pública do país (que muito perde quando ocorrem rebeliões), pela paz social, pelo inconsciente coletivo (nenhum indivíduo moralmente saudável gostaria que o Brasil fosse palco de mais um massacre do Carandiru) e por níveis aceitáveis de estrutura, em uma federação com carga tributária altíssima, sem qualquer aparente contraprestação para a sociedade. Não se pode, também, falar em juristocracia na tímida tutela, dada pelo Supremo Tribunal Federal brasileiro, no julgamento da ADPF347, quando abordou a patologia da superlotação carcerária e tomou algumas poucas providências.

\section{BREVÍSSIMA EXPOSIÇÃO DA DESUMANIDADE DA SUPERLOTAÇÃO CARCERÁRIA BRASILEIRA E ANÁLISE DO IMPACTO DE DECISÕES COMO A ADPF 347, PARA A EFETIVIDADE DE DIREITOS ESSENCIAIS SOCIAIS}

\footnotetext{
${ }^{16}$ YOUNG, op. cit., p. 26.

${ }^{17}$ IHU. Instituto Humanitas. Brasil, terceira maior população carcerária, aprisiona cada vez mais. Revista IHU ON-LINE. Reportagem de Fernando Caulyt publicada por Deutsche Welle, 12 set. 2018. Disponível em: http://www.ihu.unisinos.br/78-noticias/582668-brasil-terceira-maior-populacao-carceraria-aprisiona-cada-vezmais. Acesso em: 01jul. 2019.
} 
O Brasil tem a terceira maior população carcerária do mundo e em 2016 já contava com 726 mil pessoas presas. Identifica-se, ainda, um ritmo intenso no constante crescimento das taxas de encarceramento, como aponta o "monitor da violência", indicador resultante de uma parceria do Núcleo de Estudos da Violência (NEV), da Universidade de São Paulo - USP com o Fórum Brasileiro de Segurança Pública. O Infopen ${ }^{18}$ (Levantamento Nacional de Informação Penitenciária) corrobora os números e através de relatório anual informa que, dentre os presos, $89 \%$ estão em unidades superlotadas, o que inegavelmente ofende, desfigura e subverte a privação de liberdade, causando disfunção da pena, pelo crônico desaparelhamento. Os dados confirmam que, no Estado do Amazonas, por exemplo, há 48 pessoas em espaço destinado para 10.

Essa superlotação significa na prática que essas pessoas estão presas em condições de verdadeira tortura, sem acesso à água potável, nem a saneamento básico ou a vestuário adequado. Estão desprovidas de produtos de higiene, de trabalho, de estudo, de alimentação adequada, de remédios, em ambientes impiedosamente precários, úmidos e extremamente sujos, infestados por insetos, ratos, baratas e outros animais, como eram as masmorras medievais. Sofrem maus tratos físicos e psicológicos e são privados de muito mais do que apenas a liberdade.

Em recentíssima decisão, do mês de julho de 2019, o Supremo Tribunal Federal, no julgamento do Habeas Corpus 172.136, do Estado de São Paulo, constatou, por exemplo, que parte dos presos da cidade de Martinópolis estavam impedidos, pela administração do presídio Tacyan Menezes de Lucena, de sair de suas celas para banho de sol e não viam a luz do dia havia meses.

Nas palavras do juiz de direito da vara de execuções penais de Joinville/SC, João Marcos Buch, “[...] há uma crise humanitária sem precedentes no sistema carcerário brasileiro e o judiciário é personagem central nessa violação aos direitos humanos". ${ }^{19}$ Talvez a referência do

\footnotetext{
18 BRASIL. Ministério da Justiça e Segurança Pública. Infopen. Dezembro de 2016. Brasília, 2016. Disponível em: http://depen.gov.br/DEPEN/depen/sisdepen/infopen. Acesso em: 11jul.2019.

19 BUCH, João Marcos. Prisões brasileiras são campos de concentração. Justificando. Disponível em:http://www.justificando.com/2019/06/21/prisoes-brasileiras-sao-campos-de-concentracao-nao-quero-seradolf-eichmann-diz-juiz-brasileiro/.Acesso em: 10.jul.2019.
} 
magistrado seja em função da ausência de visitas carcerárias, legalmente previstas, que os juízes deveriam realizar nas penitenciárias ou quiçá seja alusão à falta de motivação nas suas decisões.

Mas, seja como for, certo é que o Supremo Tribunal Federal, quando importou a experiência colombiana de adjudicação e declarou o "Estado de Coisas Inconstitucional", reconhecendo o fracasso dos outros poderes na administração da questão eavocando a competência para combater causas estruturais da violação - como ocorre na hipótese de “injunção estrutural” nos EUA, quando "o Tribunal emite ordens para sanar as insuficiências orçamentais e administrativas e estabelece níveis mínimos obrigatórios de proteção dos direitos humanos"20 -,perdeu grande oportunidade de, já que estava adotando postura ativista, influenciar de fato na agenda sensível de promoção da dignidade humana, a nível realmente efetivo, pois deferiu apenas muito em parte as medidas cautelares solicitada na ADPF 437, julgando procedente somente 2 (dois) dos 8 (oito) pedidos.

Por honestidade, importante dizer que estudos sérios e recentes apontam que as sentenças dialógicas, com medidas judiciais mais moderadas, são as que causam maiores impactos ao cumprimento dos direitos sociais.

Nesse sentido:

[...] que las sentencias dialógicas, caracterizadas por derechos fuertes, medidas judiciales moderadas y seguimiento fuerte, probablemente sean las que mayor impacto tengan en el cumplimiento de los DESC. Ilustré esa hipótesis mostrando las conclusiones de un estudio de caso comparado sobre las consecuencias de tres decisiones estructurales históricas de la CCC sobre DESC. ${ }^{21}$

Mas, desde Aristóteles ${ }^{22}$ se sabe que a virtude está no meio, e, ainda assim, como muitos pedidos eram sobre descumprimentos do próprio Poder Judiciário, impossível, para um olhar mais generoso, não lamentar o resultado dos pleitos liminares da ADPF 347.Expor e comentar cada uma das invocações exordiais e cada um dos votos do julgamento é incompatível com este

\footnotetext{
${ }^{20}$ SOMBRA, Thiago Luís Santos. O "estado inconstitucional de assuntos" no sistema penitenciário brasileiro:o encantamento do transplante legal. Int'l J. Const. L. Blog, 2015. Disponível: http://www.iconnectblog.com/2015/09/the-unconstitutional-state-of-affairs-in-brazils-prison-system-theenchantment-of-legal-transplantation/. Acesso em: 11.jul.2019.

${ }^{21}$ GARAVITO, César Rodríguez. Más allá del cumplimiento: cómo analizar y aumentar el impacto de los tribunales. In: LANGFORD, Malcolm; GARAVITO, Cesar Rodríguez; ROSSI, Julieta (editores). La lucha por los derechos sociales, los fallos judiciales y a disputa política por su cumplimiento.Bogotá: Dejusticia, 2017, p. 129.

${ }^{22}$ ARISTÓTELES. Ética a Nicômaco. Coleção Os Pensadores. São Paulo: Nova Cultural, 1987.
} 
espaço. O que importa, nesse momento, é dizer que a decisão é um típico e polêmico exemplo de tentativa de "jurisdição constitucional de efeito pedagógico" e "decisão estímulo". O ministro Gilmar Mendes inclusive aludiu, expressamente, ao que chamou de "caráter plástico da decisão", e outros realizaram menção expressa aos conceitos de medidas estruturantes, de forma inédita no Brasil. A decisão, a nível técnico, padece de problemas graves.

Para Lenio Streck, por exemplo, o objeto do controle de constitucionalidade são normas jurídicas e não a realidade empírica, motivo pelo qual não se poderia declarar a inconstitucionalidade de coisas. O jusfilósofo, ao comentar a decisão, disse que foi um ativismo camuflado, com tese tão abrangente que é difícil combatê-lo. E alertou para o grande risco de que isso seja utilizado como um enorme guarda-chuva debaixo do qual se pode colocar tudo aquilo que o ativismo quiser. De maneira tal que não se teria qualquer controle sobre os limites para que uma situação seja considerada inconstitucional de forma estrutural, a ponto de exigir uma intervenção proativa do Judiciário e obrigar a implementação de políticas públicas. ${ }^{23}$

De 2015 até o momento, apesar da edição da súmula 56 (que combateu em certa medida, ilegal excesso de execução, impedindo a manutenção de condenados em regime prisional mais gravoso) e de certa incorporação do princípio do numerusclausulus ${ }^{24}$,que gerou algumas medidas e portarias, os dados não oficiais (já que os dados oficiais mais recentes são de 2016)informam que a população carcerária já está na faixa de 900 mil presos. A quantidade de vagas pouco não cresceu, estando muito aquém da proporção desse aparente vultuoso crescimento de presos.

O Conselho Nacional de Justiça constatou que mais de 140 mil mandados de prisão estão em aberto. Tudo isso parece testemunhar, no sentido de que é muito difícil aumentar o impacto dos tribunais, mesmo quando eles prestam alguma tutela que se pretende efetiva, na área dos direitos sociais.

\footnotetext{
${ }^{23}$ STRECK, Lenio L. As razões pelas quais Dworkin não admite discricionarismos na decisão judicial e porque em Alexy ocorre a "consagração da discricionariedade dos operadores jurídicos. In:Lições de crítica hermenêutica do Direito.2 ed. Porto Alegre: Livraria do Advogado, 2016.

${ }^{24} \mathrm{O}$ Ministro Ricardo Lewandowski, na ADPF no 347, afirmou que: "Eles [os juízes] têm que observar estritamente o espaço físico das prisões, porque senão, se o juiz determinar a prisão para uma penitenciária, uma cadeia pública, para uma cela onde cabem vinte pessoas e já existem cem pessoas, evidentemente este mandado será cumprido em uma situação muito mais gravosa do que a própria sentença determina. (ADPF 347 MC, Relator(a): Min. Marco Aurélio, Tribunal Pleno, julgado em 09/09/2015, Processo eletrônico DJe-031 Div.: 18-02-2016, pub. 19 fev. 2016, p. 111).
} 
Assim, mais adequada não poderia ser a reflexão de Garavito:

\begin{abstract}
Urge especialmente este tipo de análisis porque la preocupación por el impacto de las sentencias es una de las cuestiones más presentes en el pensamiento de los litigantes y los jueces. Después de todo, generar impactos concretos que mejoren el acceso a bienes y servicios, así como su calidad - como una vivienda digna o servicios de salud - es lo que hace que los litigantes y los activistas recurran a los tribunales. En ese mismo sentido, si las sentencias no tienen consecuencias prácticas, sería insensato que los tribunales incurrieran en los elevados costos institucionales asociados con sus sentencias activistas sobre DESC, especialmente en casos estructurales que implican negociaciones prolongadas y tensiones con los organismos administrativos responsables de ejecutarlas. Una vez que haya pasado la euforia sobre el caso, la pregunta que estará en la mente de todos será: ¿valió la pena? ${ }^{25}$
\end{abstract}

Ainda, é necessária atenção ao que a doutrina norte-americana chamou de "efeito backlash", que, no Brasil, foi perfeitamente ilustrado com a questão das vaquejadas. ${ }^{26}$ Tal efeito teve seu advento no famoso caso Furmanv.Georgia, ainda na década de noventa. Naquela oportunidade, tratava-se da (in)compatibilidade da pena de morte com a oitava emenda da constituição norte-americana, que proibia as penas cruéis.

Por acirrados 5 a 4, a pena de morte foi considerada incompatível com o ordenamento jurídico, pela Suprema Corte dos Estados Unidos. Porém, a decisão gerou fortíssima e ativa reação social de movimentos contrários a ela e totalmente favoráveis à pena de morte. A força da pressão terminou por aprovar leis tratando com ainda maior rigor o tema, em sentido diametricamente oposto ao provimento judicial. O efeito backlash é, assim, uma resposta social contrária às decisões do Poder Judiciário que, diante de temas sensíveis, interpreta a constituição de certa forma, ativista, e desencadeia atividade legiferante, no sentido contrário, em reação do poder político.

Ao passo que cirurgicamente:

[...] se mostra temerário quando tratamos de ativismo judicial, pois pode acarretar um retrocesso no assunto tratado pela decisão caso não haja apoio popular. Todavia, entende-se que não se pode enfraquecer a atuação judicial em razão do receio deste efeito, pois atualmente vive-se um Constitucionalismo Democrático, oposto ao dito Constitucionalismo Popular, em que se deve, portanto, ampliar a legitimidade

\footnotetext{
${ }^{25}$ GARAVITO, César Rodríguez. Más allá del cumplimiento: cómo analizar y aumentar el impacto de los tribunales. In: LANGFORD, Malcolm; GARAVITO, Cesar Rodríguez; ROSSI, Julieta (editores). La lucha por los derechos sociales, los fallos judiciales y a disputa política por su cumplimiento.Bogotá: Dejusticia, 2017, p. 129.

${ }^{26}$ A EC 96/2017 declarou que não se consideram cruéis práticas desportivas que utilizem animais, desde que sejam manifestações culturais.Isso ocorreu após o Supremo decidir que a proibição da crueldade animal deveria prevalecer sobre a tradição cultural, opondo-se à realização das polêmicas vaquejadas.
} 
democrática garantindo os direitos não apenas da maioria como igualmente e talvez principalmente das minorias. ${ }^{27}$

Evidente também que os juízes, pela ausência de previsão orçamentária e informação adequada, não conseguem, muitas vezes, medir ou antecipar os impactos distributivos e podem sacrificar, ao invés de proteger, direitos. Infelizmente no Brasil até o momento, as experiências práticas parecem ter comprovado que o poder judiciário não possui a expertise necessária para efetivar direitos sociais.

A dificuldade de diálogos institucionais proveitosos e de fiscalização do cumprimento das medidas parece ser o principal problema. As providências exigem múltiplas atividades, e mesmo após o provimento judicial, a questão volta ao problema original, sem grandes progressos ou no pior dos casos, com retrocessos lamentáveis. Assim, a tensão democrática que a desconformação da jurisdição aos parâmetros, em certa medida gera, com o ativismo, talvez não compense, na prática, pelos efeitos que (não) é capaz de construir no âmbito de direitos sociais. Pelo menos a experiência brasileira, até agora, parece ser nesse sentido.

\section{CONSIDERAÇÕES FINAIS}

Ante todo exposto, é possível afirmar que as sentenças dialógicas, com medidas judiciais estruturantes moderadas, parecem (a despeito de serem, não raras vezes a única forma de impulsionar o sistema ao progresso humano, em democracias de tardia modernização) não terem ainda encontrado o caminho do tato, da coerência, da razoabilidade, da análise de proporcionalidade e da medida na qual realmente possam proporcionar alguma evolução a justificar a pouca deferência. E contribuir, efetivamente, para o estímulo e progresso na promoção da dignidade do ser humano. Porém, se reconhece que sobre a situação carcerária brasileira, o Poder Judiciário era o destinatário da maioria das medidas, solicitadas cautelarmente na ADPF 347, como um pequeno passo em direção a humanização do caos

${ }^{27}$ SILVA, Vanessa Jéssica Mansur. A evolução do ativismo judicial: o papel do judiciário como legislador positivo. Conteúdo Jurídico, Publicado em 08 fev. 2019. Brasília, 2019. Disponível em: https://conteudojuridico.com.br/consulta/Artigos/52639/a-evolucao-do-ativismo-judicial-o-papel-dojudiciario-como-legislador-positivo. Acesso em: 13 set. 2019. 
assustador do sistema penitenciário pátrio. E o Supremo está juntando AR há 4 meses, na chance que ainda tem de fazer diferença na inércia dos poderes sobre essa violação massiva e persistente de direitos básicos fundamentais das pessoas presas, privadas de existência digna. Afinal, já que já declarou o "estado de coisas inconstitucionais" agora que "embale a criança".

\section{REFERÊNCIAS}

ABRAMOVICH, Victor; COURTIS, Christian. Los derechos sociales como derechos exigibles.Madrid: Trotta, 2002.

ALMEIDA, Renato Franco de; COELHO, Aline Bayerl. Princípio da demanda nas ações coletivas do Estado Social de Direito.Revista de Direito do Consumidor, n. 50. São Paulo: Revista dos Tribunais, abr./jun., 2004.

ATRIA, Fernando. "Existem direitos sociais? "In:MELLO, Cláudio Ari (coord.). Os desafios dos direitos sociais. Porto Alegre: Livraria do Advogado, 2005.

ARISTÓTELES. Ética a Nicômaco. Coleção Os Pensadores. São Paulo: NovaCultural, 1987.

BONAVIDES, Paulo. Curso de Direito Constitucional. 13 ed. São Paulo: Malheiros, 2003.

BRASIL. Ministério da Justiça e Segurança Pública.Infopen. Dezembro de 2016. Brasília, 2016. Disponível em: http://depen.gov.br/DEPEN/depen/sisdepen/infopen. Acesso em: 11jul.2019.

BRASIL. Supremo Tribunal Federal. ADPF 347. Protocolada em 27 de maio de 2015. Brasília, 2015. Disponível em: http://portal.stf.jus.br/processos/detalhe.asp?incidente=4783560. Acesso em: 11jul.2019.

BUCH, João Marcos. Prisões brasileiras são campos de concentração.Justificando. Disponível em: $\quad$ http://www.justificando.com/2019/06/21/prisoes-brasileiras-sao-campos-deconcentracao-nao-quero-ser-adolf-eichmann-diz-juiz-brasileiro/. Acesso em: 10 jul.2019.

CAENEGEM, Raoul Charles Van. Uma introdução histórica ao direito privado. Trad. Carlos Eduardo Lima Machado. 2 ed. São Paulo: Martins Fontes, 1999.

DWORKIN, Ronald. Levando os direitos a sério. São Paulo: Martins Fontes, 2002.

FACHIN, Luiz Edson. Estatuto jurídico do patrimônio mínimo. Rio de Janeiro: Renovar, 2001.

FACHIN, Luiz Edson. Teoria crítica do direito civil. 2 ed. Rio de Janeiro: Renovar, 2003.

GARAVITO, César Rodríguez. Más allá del cumplimiento: cómo analizar y aumentar el impacto de los tribunales. In: LANGFORD, Malcolm; GARAVITO, Cesar Rodríguez; ROSSI, 
Julieta (editores). La lucha por los derechos sociales, los fallos judiciales y a disputa política por su cumplimiento.Bogotá: Dejusticia, 2017.

IHU. Instituto Humanitas. Brasil, terceira maior população carcerária, aprisiona cada vez mais. Revista IHU ON-LINE. Reportagem de Fernando Caulyt publicada por Deutsche Welle, 12set.2018. Disponível em: http://www.ihu.unisinos.br/78-noticias/582668-brasil-terceiramaior-populacao-carceraria-aprisiona-cada-vez-mais. Acesso em: 01jul.2019.

MORAES, Alexandre de. Direito constitucional. 13ª . ed. São Paulo: Atlas, 2003.

SARLET, Ingo Wolfgang; FIGUEIREDO, Mariana Filchtiner. Reserva do possível, mínimo existencial e direito à saúde: algumas aproximações. Revista de Doutrina da $4^{\mathrm{a}}$ Região, Porto Alegre, n. 24, jul, 2008. Disponível http://www.revistadoutrina.trf4.jus.br/artigos/edicao024/ingo_mariana.html.

Acessoem: 12set.2019.

SILVA, Vanessa Jéssica Mansur. A evolução do ativismo judicial: o papel do Judiciario como legislador positivo. Conteúdo Jurídico, Publicado em 08 fev. 2019. Brasília, 2019. Disponível em: https://conteudojuridico.com.br/consulta/Artigos/52639/a-evolucao-do-ativismo-judicialo-papel-do-judiciario-como-legislador-positivo. Acesso em: 13 set. 2019.

STRECK, Lenio L. As razões pelas quais Dworkin não admite discricionarismos na decisão judicial e porque em Alexy ocorre a "consagração da discricionariedade dos operadores jurídicos. In:Lições de crítica hermenêutica do Direito. 2 ed. Porto Alegre: Livraria do Advogado, 2016.

SOMBRA, Thiago Luís Santos. O "estado inconstitucional de assuntos" no sistema penitenciário brasileiro: o encantamento do transplante legal. Int'l J. Const. L. Blog, 2015. Disponível: http://www.iconnectblog.com/2015/09/the-unconstitutional-state-of-affairs-inbrazils-prison-system-the-enchantment-of-legal-transplantation/. Acesso em: 11jul.2019.

YOUNG, Katharine Galloway. Proportionality, reasonableness, and economic social rights.In: JACKSON; Vicki C. TUSHNET, Mark (eds.). Proportionality:new frontiers, new challenges, 2017.

Data de Submissão: 20/09/2019

Data de Aceite: 20/04/2020 